\title{
Revista Colombiana de

\section{Characterization of dyspnea in chronic diseases and heart failure in patients in a Family Health Program}

\author{
Diana M.M. Ceron ${ }^{\mathrm{a}, \mathrm{b}, *}$, Maria Luiza Garcia Rosa ${ }^{\mathrm{a}}$, Antônio J.L. Jorge ${ }^{\mathrm{a}}$, \\ Dayse M.S. Correia ${ }^{c}$, Hye C. Kang ${ }^{d}$, Evandro T. Mesquita ${ }^{e}$, \\ Julio César Grijalba Velasco ${ }^{e}$, Ronaldo Gismondi ${ }^{\mathrm{e}}$, Wolney de Andrade Martins ${ }^{\mathrm{e}}$
}

\footnotetext{
a Universidade Federal Fluminense, Department of Epidemiology and Biostatistics, Río de Janeiro, Brasil

b Universidad del Cauca, Departamento de Medicina Social y Salud Familiar, Popayán, Colombia

c Universidade Federal Fluminense, Department of Nursing and Administration Fundamentals, Escola de Enfermagem Aurora de Afonso Costa, Departamento de Fundamentos de Enfermagem e Administração, Niteroi, Brazil

d Universidade Federal Fluminense, Department of Pathology, Río de Janeiro, Brasil

e Universidade Federal Fluminense, Department of Clinical Medicine, Río de Janeiro, Brasil
}

Received 13 January 2018; accepted 7 July 2019

Available online 4 November 2019

\section{KEYWORDS \\ Dyspnea; \\ Heart Failure; \\ Depression; \\ Chronic obstructive \\ pulmonary disease; \\ Paroxysmal nocturnal \\ dyspnea}

\begin{abstract}
Background: Dyspnea is the most common symptom in heart failure. In the elderly, it is common in chronic obstructive pulmonary disease and depression.

Objective: To estimate the prevalence of dyspnea on exertion, orthopnea and paroxysmal nocturnal dyspnea and its association with chronic diseases in primary care.

Methods: A cross-sectional study, part of the Digitalis Study, including 633 individuals, between 45 to 99 years old, registered in a primary care program in Niteroi, Brazil. All participants underwent clinical evaluations, blood and urine collection, and responded to a questionnaire in a single day. Self-reports were used for the diagnosis of diseases.

Results: Of the 633 individuals, 30\% had dyspnea. In the crude analysis, chronic obstructive pulmonary disease showed the strongest associations with the three types of dyspnea, followed by depression and heart failure. Chronic obstructive pulmonary disease alone did not present any cases of paroxysmal nocturnal dyspnea, and heart failure alone showed a very strong relationship with this type of dyspnea.

Conclusions: The different behavior of the associations of the types of dyspnea with major chronic diseases in patients in primary care can help in the better characterization of patients with heart failure.

(c) 2019 Sociedad Colombiana de Cardiología y Cirugía Cardiovascular. Published by Elsevier España, S.L.U. This is an open access article under the CC BY-NC-ND license (http:// creativecommons.org/licenses/by-nc-nd/4.0/).
\end{abstract}

\footnotetext{
* Corresponding author.

E-mail address: mcdianamaria@gmail.com (D.M.M. Ceron).
} 


\section{PALABRAS CLAVE}

Disnea;

Insuficiencia

cardíaca;

Depresión;

Enfermedad

pulmonar obstructiva

crónica;

Disnea paroxística

nocturna

\section{Caracterización de la disnea en pacientes con enfermedades crónicas e insuficiencia cardíaca de un Programa de Salud Familiar}

\section{Resumen}

Introducción: La disnea es el síntoma más común en la insuficiencia cardíaca. En los ancianos es común en la enfermedad pulmonar obstructiva crónica y la depresión.

Objetivo: Estimar la prevalencia de disnea de esfuerzo, ortopnea y disnea paroxística nocturna y su asociación con enfermedades crónicas en la atención primaria.

Métodos: Estudio transversal, parte del estudio Digitalis, que incluyó a 633 individuos, entre 45 y 99 años de edad, registrados en un programa de atención primaria en Niterói, Brasil. Todos los participantes se sometieron a evaluaciones clínicas, recolección de sangre y orina, y respondieron a un cuestionario en un solo día. Se usaron autorrelatos para el diagnóstico de las enfermedades.

Resultados: De los 633 individuos, el 30\% presentó disnea. En el análisis crudo la enfermedad pulmonar obstructiva crónica mostró las asociaciones más fuertes con los tres tipos de disnea, seguidos por la depresión y la insuficiencia cardíaca. La enfermedad pulmonar obstructiva crónica, evaluada de forma aislada, no presentó ningún caso de disnea paroxística nocturna, y la insuficiencia cardíaca por sí sola mostró una relación muy fuerte con este tipo de disnea.

Conclusiones: El comportamiento diferente de las asociaciones de los tipos de disnea con las principales enfermedades crónicas en pacientes en atención primaria puede ayudar a una mejor caracterización de los pacientes con insuficiencia cardíaca.

(c) 2019 Sociedad Colombiana de Cardiología y Cirugía Cardiovascular. Publicado por Elsevier España, S.L.U. Este es un artículo Open Access bajo la licencia CC BY-NC-ND (http:// creativecommons.org/licenses/by-nc-nd/4.0/).

\section{Introduction}

Dyspnea is a subjective symptom of shortness of breath and is perceived as unpleasant by patients. ${ }^{1}$ It is the symptom most commonly reported by patients with heart failure (HF), encompassing dyspnea on exertion (DE), orthopnea and the paroxysmal nocturnal dyspnea (PND). ${ }^{2}$ However, in older people this symptom is common in other diseases such as chronic obstructive pulmonary disease (COPD), asthma and depression, for example, with a prevalence ranging from 20 to $60 \% .^{3}$

HF stands out among the cardiovascular illnesses, thus becoming a serious public health across the world. ${ }^{4}$ In primary care, access to echocardiography, an essential tool for the diagnosis of HF, is more restricted. ${ }^{5}$ The early diagnosis of HF is crucial to reverse cardiac remodeling before the onset of symptoms. ${ }^{6}$ Although previous studies have shown that the presence of dyspnea had limited value in diagnosing heart failure ${ }^{7,8}$ the mapping of the association of the different types of dyspnea with the chronic diseases most prevalent in the community, can assist in the better characterization of patients with $\mathrm{HF}$ in primary care within an economically challenged population. We have not found such studies in Brazilian literature.

This article aims to estimate the prevalence of dyspnea on exertion, orthopnea and paroxysmal nocturnal dyspnea and their association with chronic diseases, and especially with heart failure, COPD and depression in patients between 45 and 99 years of age who attended the Family Health Program (PMF) in the city of Niterói, Rio de Janeiro.

\section{Methods}

This cross-sectional study included 633 individuals aged $\geq 45$ to 99 years of age who were registered in the Primary Care Program of Niteroi city, an urban, medium-sized town with 487,562 inhabitants in Rio de Janeiro State, Brazil. The data were collected from July 2011 to December 2012 and aimed to estimate the prevalence of chronic diseases identified from validated instruments and recommendations according to the American College of Cardiology/American Heart Association, Brazilian Society of Cardiology, American Diabetes Association, World Health Organization, The PHQ validated in Brasil, Berlin Questionnaire. See the details in the publication. ${ }^{9}$

The participants responded to a questionnaire that asked for information related to co-morbidities and demographics as well as socioeconomic and lifestyle factors. Medical staff members collected personal and family medical histories. Trained researchers measured the participants' blood pressure as well as collected blood and urine samples. Laboratory tests included BNP levels, 12-lead electrocardiogram (ECG), and tissue Doppler echocardiography (TDE) were performed.

The outcomes were the three types of dyspnea and its presence was defined from positive answers to the questions: "Do you feel shortness of breath with exertion?", "Do you feel shortness of breath when lying down?" and "Do you wake up at night, after about four hours of being asleep, feeling shortness of breath?'. The diseases most associated with dyspnea were considered as exposure: HF, COPD and depression. Asthma, thyroid disease, prior angina and prior myocardial infarction were considered as 
potential confounders. All of the above diseases were considered present, from the positive response to the questions:

"Has a doctor ever told you that you have or had or...", and were considered as self-reported diagnoses.

Body weight was measured by a digital electronic scale (PL80, Filizola, Brazil) and height by a portable digital stadiometer (Kirchnner Wilhelm, Medizintechnik, Germany). Body mass index (BMI) was calculated as the ratio of weight in kilograms to height in meters squared. Patients with a BMI $\left(\mathrm{kg} / \mathrm{m}^{2}\right) \geq 30$ were considered obese. ${ }^{10}$ For the classification of depression we used the responses from the Patient Health Questionnaire-9 (PHQ-9), ${ }^{11}$ validated in Brazil ${ }^{12}$ and those who had a score of 3, 4 or 5 (depression moderate, moderately severe and severe) were considered positive. ${ }^{11}$

\section{Statistical analysis}

Statistical analysis was performed with SPSS software version 21.0 (Chicago, Illinois, USA). Categorical variables were expressed as absolute numbers and percentages. For comparisons between groups, the chi-square test was used. Crude odds ratio $\left(O R_{c}\right)$ for each type of dyspnea was estimated for each variable. For HF, COPD and depression, crude and adjusted ORs were also estimated considering, for each of the diseases, only cases without the other two diseases. The adjusted odds ratio $\left(\mathrm{OR}_{\mathrm{a}}\right)$ were estimated by logistic regression models. The variables associated with each type of dyspnea at a 0.10 level in the bivariate analysis were included in the multiple models. Heart failure, heart attack and angina were not included because heart attack and less angina are risk factors for heart failure. The level of statistical significance was $5 \%$.

The Ethics Committee of the Institution under CAAE number 0077.0.258.000-10 approved the study protocol and all participants signed the consent form.

\section{Results}

The study included 633 individuals between 45 and 99 years of age $(59.6 \pm 10.4$ years; $62 \%$ female) who completed clinical and laboratory evaluations. Among the individuals studied, the majority presented $<\mathrm{R} \$ 800.00$ (75.6\%) and hypertension (72.7\%). The prevalence of HF in this population was $8.2 \%$, and the prevalence of other diseases traditionally associated with dyspnea, from a selfreported diagnosis, ranged from $30.2 \%$ (obesity) to $3.6 \%$ (COPD) (Table 1).

Dyspnea was present in $29.2 \%$ of the participants and the most prevalent type was dyspnea on exertion (26.5\%).

In the crude analysis, COPD presented the strongest associations with the three dyspnea types, $\mathrm{OR}_{\mathrm{b}}$ scores higher than 4, followed by depression and HF, which had similar $\mathrm{OR}_{\mathrm{b}}$ values (Table 2 ).

The prevalence of heart failure without COPD and depression was $69,23 \%$, the prevalence of COPD without depression and $\mathrm{HF}$ was $63,63 \%$ and the prevalence of depression without COPD and HF was $85,52 \%$.

Table 3 shows crude and adjusted odds ratios of dyspnea on exertion, orthopnea and paroxysmal nocturnal dyspnea according to HF, COPD and depression, each of them in the absence of the others. The two major changes compared to Table 2 occurred in relation to PND. HF (without COPD and without depression) had the highest $\mathrm{OR}_{\mathrm{b}}$ score and COPD (without HF and without depression) did not present any case. In the adjusted analysis, HF (without COPD and without depression) showed a greater association with PND, $\left(O R_{a}=7.72\right)$, and dyspnea on exertion and orthopnea $O R_{a}$ scores were lower compared to $\mathrm{OR}_{\mathrm{b}}$. COPD associations with dyspnea on exertion and orthopnea were weak. As for the associations between depression and the three types of dyspnea, no significant changes in relation to crude analysis were detected.

\section{Discussion}

In the present study we observed that about $30 \%$ of the subjects (45 to 99 years old) reported some type of dyspnea, and dyspnea on exertion was the most prevalent type (26.5\%).

COPD was the disease that showed strongest association with the three types of dyspnea, with crude OR values above 4, followed by depression and HF. The scenario changed when these diseases were considered in isolation, especially in relation to the PND: in this case COPD did not present any cases and the association with HF was higher both in the crude and adjusted analysis.

In HF, paroxysmal nocturnal dyspnea is caused by the decreased ability of the heart to fill and empty, producing high pressure in the blood vessels around the lung. ${ }^{13}$ The symptom has been used to establish the diagnosis of heart failure and NYHA functional class. ${ }^{14}$ A 2010 study of 276 patients diagnosed with HF reported a prevalence of paroxysmal nocturnal dyspnea (self-reported) of $23.6 \%$ in the group of outpatients, equal to that found in this study. ${ }^{15}$ COPD is considered an obstructive process in which there is an increase of airway resistance for the exhalation of air, leading to dyspnea. ${ }^{16}$ Besides some different aspects, the pathophysiological processes of the two diseases overlap each other, a fact that also happens to their clinical signs and symptoms frequently. ${ }^{17}$ Additionally, COPD and HF patients share many terms to describe lack of breath, and experience dyspnea with a similar frequency, ${ }^{18}$ another fact that contributes to the difficulty in differentiating between the two diseases. In this study, the prevalence of both self-reported diseases was low $(\mathrm{HF}=8.2$ and $\mathrm{COPD}=3.5 \%)$ and only three (5.8\%) of the 52 individuals who said they had prior diagnosis of HF said they had also a diagnosis of COPD, and is consistent with results of studies in the community, which reported prevalence of COPD in patients with HF ranging from $20 \%$ to $35 \% .^{17}$

Some studies investigating the sensitivity and specificity of dyspnea for HF found low sensitivity and high specificity results, but these were not compared with the COPD. ${ }^{7,8}$

The association between anxiety, depression and respiratory symptoms is an evidence widely described in literature. ${ }^{19}$ The relationship of cause and effect between psychological factors and dyspnea is not yet completely clear. $^{20}$ There is evidence that dyspnea may induce psychiatric disorders, while other studies indicate that psychological illnesses, particularly depression, intensify the subjective feeling of dyspnea. ${ }^{20}$ Previous studies have documented evidence of depression in HF patients. ${ }^{21}$ It was reported that HF and depression coexist in about a 
Table 1 Clinical characteristics of subjects studied and its prevalence in the presence of dyspnea on exertion, orthopnea and paroxysmal nocturnal dyspnea.

\begin{tabular}{|c|c|c|c|c|}
\hline & n (\%) & $\begin{array}{l}\text { Dyspnea on exertion } \\
\mathrm{n}(\%)\end{array}$ & $\begin{array}{l}\text { Orthopnea } \\
\mathrm{n}(\%)\end{array}$ & $\begin{array}{l}\text { Paroxysmal nocturnal dyspnea } \\
\mathrm{n}(\%)\end{array}$ \\
\hline \multicolumn{5}{|c|}{$B M I \mathrm{~kg} / \mathrm{m}^{2}$} \\
\hline$\geq 30$ & $190(30,2)$ & $65(34,2)$ & $23(12,1)$ & $13(6,8)$ \\
\hline$<30$ & $439(69,8)$ & $103(23,5)$ & $33(7,5)$ & $31(7,1)$ \\
\hline \multicolumn{5}{|c|}{ Anemia } \\
\hline Yes & $63(10,2)$ & $15(23,8)$ & $2(3,2)$ & $3,0(4,8)$ \\
\hline No & $554(89,8)$ & $148(26,7)$ & $53(9,6)$ & $41(7,4)$ \\
\hline \multicolumn{5}{|c|}{ Thyroid disease } \\
\hline Yes & $47(7,4)$ & $21(44,7)$ & $9,0(19,1)$ & $7(14,9)$ \\
\hline No & $586(92,6)$ & $147(25,1)$ & $47(8,0)$ & $38(6,5)$ \\
\hline \multicolumn{5}{|c|}{ Asthma } \\
\hline Yes & $83(13,1)$ & $37(44,6)$ & $12(14,5)$ & $11(13,3)$ \\
\hline No & $550(86,9)$ & $131(23,8)$ & $44(8,0)$ & $34(6,2)$ \\
\hline \multicolumn{5}{|c|}{ Chronic hypertension } \\
\hline Yes & $460(72,7)$ & $119(25,9)$ & $41(8,9)$ & $33(7,2)$ \\
\hline No & $173(27,3)$ & $49(28,3)$ & $15(8,7)$ & $12(6,9)$ \\
\hline \multicolumn{5}{|c|}{ Diabetes } \\
\hline Yes & $158(24,8)$ & $45(28,7)$ & $17(10,8)$ & $13(8,3)$ \\
\hline No & $475(75,2)$ & $123(25,9)$ & $39(8,2)$ & $32(6,7)$ \\
\hline \multicolumn{5}{|c|}{ Angina pectoris } \\
\hline Yes & $38(6,0)$ & $20(52,6)$ & $10(26,3)$ & $8(21,1)$ \\
\hline No & $595(94,0)$ & $148(24,9)$ & $46(7,7)$ & $37(6,2)$ \\
\hline \multicolumn{5}{|c|}{ Myocardial infarction } \\
\hline Yes & $27(4,3)$ & $13(48,1)$ & $7,0(25,9)$ & $6(22,2)$ \\
\hline No & $606(95,7)$ & $155(25,6)$ & $49(8,1)$ & $39(6,4)$ \\
\hline \multicolumn{5}{|l|}{$H F$} \\
\hline Yes & $52(8,20$ & $29(55,8)$ & $12(23,1)$ & $12(23,1)$ \\
\hline No & $581(91,8)$ & $139(23,9)$ & $44(7,6)$ & $33(5,7)$ \\
\hline \multicolumn{5}{|l|}{$C O P D$} \\
\hline Yes & $22(3,5)$ & $14(63,6)$ & $7(31,8)$ & $5(22,7)$ \\
\hline No & $611(96,5)$ & $154(25,2)$ & $49(8,0)$ & $40(6,5)$ \\
\hline \multicolumn{5}{|c|}{ Depression } \\
\hline Yes & $138(21,9)$ & $70(50,7)$ & $27(19,6)$ & $65(34,2)$ \\
\hline No & $492(78,1)$ & $97(19,7)$ & $28(5,7)$ & $103(23,5)$ \\
\hline
\end{tabular}

BMI, body mass index; HDL, high density lipoprotein; TG, triglycerides; Anemia, Hemoglobin level of $13 \mathrm{~g} / \mathrm{dl}$ for men and $12 \mathrm{~g} / \mathrm{dl}$ for women; HF, heart failure; COPD, chronic obstructive pulmonary disease. Four individual did not have anthropometric data; four individuals did not have hemogram (poor venous access) and 18 did not answer all the nine questions of the Patient Health Questionnaire-9.

quarter of cases, which was also found in the study presented here. In our study we observed that independent associations between each disease (heart failure or depression) and dyspnea were similar, a framework that changed when the two diseases were considered individually in relation to PND. Its association to HF was greater. Anxiety and depression can increase the intensity of dyspnea creating an impaired cardiac function and may contribute to the disability rate associated with dyspnea.

Although the prevalence of asthma was greater than the prevalence of COPD in this study, its association with the three types of dyspnea was less pronounced. In this study, of the 52 patients with self-reported HF, $11.5 \%$ also reported asthma. Asthma, more recognized as a disease of childhood and young adults, is sub-diagnosed in older people and can be confused with COPD and HF. ${ }^{22}$

In both asthma and COPD there is an increase in airway resistance for exhalation leading to dyspnea, and so, it is difficult to differentiate COPD and asthma in clinical practice, especially in a primary care environment. ${ }^{23}$

Thyroid disease, angina and infarction, also self-reported conditions, showed a similar pattern of association between them: clear crude and statistically significant associations with dyspnea on exertion, orthopnea, and PND. Patients who experience an acute myocardial infarction often describe discomfort in the retrosternal region and inability to catch 
Table 2 Crude odds ratios of dyspnea on exertion, orthopnea and paroxysmal nocturnal dyspnea according to metabolic and clinical conditions.

\begin{tabular}{|c|c|c|c|c|c|c|}
\hline & \multicolumn{2}{|c|}{ Dyspnea on exertion } & \multicolumn{2}{|c|}{ Orthopnea } & \multicolumn{2}{|c|}{ Paroxysmal nocturnal dyspnea } \\
\hline & \multicolumn{2}{|l|}{ ORc } & \multicolumn{2}{|l|}{ ORc } & \multicolumn{2}{|c|}{ ORc } \\
\hline & (IC95\%) & $\mathrm{p}$ value & (IC95\%) & $\mathrm{p}$ value & (IC95\%) & $\mathrm{p}$ value \\
\hline BMI kg/m² $(\geq 30 /<30)$ & $1,69(1,16-2,46)$ & 0.005 & $69(0,96-2,97)$ & 0.089 & $0,96(0,49-1,89)$ & 1.000 \\
\hline Anemia & $0,85(0,46-1,57)$ & 0.730 & $0,31(0,07-1,30)$ & 0.146 & $0,62(0,18-2,08)$ & 0.441 \\
\hline Thyroid disease & $2,41(1,31-4,41)$ & 0.006 & $2,71(1,23-5,95)$ & 0.020 & $2,52(1,06-6,01)$ & 0.062 \\
\hline Asthma & $2,57(1,60-4,13)$ & 0.000 & $1,94(0,98-3,85)$ & 0.085 & $2,31(1,12-4,77)$ & 0.035 \\
\hline Chronic hypertension & $0,88(0,59-1,30)$ & 0.602 & $1,03(0,55-1,91)$ & 1.000 & $1,03(0,52-2,05)$ & 1.000 \\
\hline Diabetes & $1,15(0,76-1,71)$ & 0.564 & $1,35(0,74-2,47)$ & 0.401 & $1,25(0,63-2,44)$ & 0.636 \\
\hline Angina pectoris & $3,35(1,72-6,51)$ & 0.000 & $4,26(1,95-9,31)$ & 0.000 & $4,02(1,72-9,38)$ & 0.002 \\
\hline Myocardial infarction & $2,70(1,24-5,87)$ & 0.017 & $3,97(1,60-9,87)$ & 0.004 & $4,15(1,58-10,88)$ & 0.006 \\
\hline $\mathrm{HF}$ & $4,01(2,25-7,16)$ & 0.000 & $3,66(1,79-7,48)$ & 0.000 & $4,98(2,39-10,38)$ & 0.000 \\
\hline COPD & $5,19(2,13-12,61)$ & 0.000 & $5,35(2,08-13,74)$ & 0.001 & $4,19(1,17-11,96)$ & 0.013 \\
\hline Depression & $4,19(2,80-6,25)$ & 0.000 & $4,03(2,28-7,11)$ & 0.000 & $2,68(1,42-5,06)$ & 0.003 \\
\hline
\end{tabular}

BMI, body mass index; HDL, high density lipoprotein; TG, triglycerides; Anemia, Hemoglobin level of $13 \mathrm{~g} / \mathrm{dL}$ for men and $12 \mathrm{~g} / \mathrm{dL}$ for women; HF heart failure; COPD, chronic obstructive pulmonary disease; ORc, crude odds ratio.

Table 3 Crude and adjusted odds ratios of dyspnea on exertion, orthopnea and paroxysmal nocturnal dyspnea according to the presence of HF, COPD and depression individually.

\begin{tabular}{|c|c|c|}
\hline & \multicolumn{2}{|c|}{ Dyspnea on exertion } \\
\hline & ORc (IC95\%) & ORa (IC95\%)a \\
\hline Heart failure & $4.03(2.00-8.15)$ & $3,87(1,77-8,48)$ \\
\hline Chronic obstructive pulmonary disease & $5.04(1.72-14.80)$ & $5,07(1,43-17,90)$ \\
\hline \multirow[t]{3}{*}{ Depression } & $4,25(2,74-6.61)$ & $3,44(2,12-5,56)$ \\
\hline & \multicolumn{2}{|c|}{ Orthopnea } \\
\hline & ORc (IC95\%) & ORa (IC95\%)b \\
\hline Heart failure & $4.21(1.57-11.27)$ & $3,93(1,30-11,86)$ \\
\hline Chronic obstructive pulmonary disease & $3.51(0.73-16.74)$ & $2,90(0,35-23,70)$ \\
\hline \multirow[t]{3}{*}{ Depression } & $3.79(1.93-7.43)$ & $2,52(1,22-5,24)$ \\
\hline & \multicolumn{2}{|c|}{ Paroxysmal nocturnal dyspnea } \\
\hline & ORc (IC95\%) & ORa (IC95\%)c \\
\hline Heart failure & $6.71(2.98-16.78)$ & $7,72(2,88-20,68)$ \\
\hline \multicolumn{3}{|l|}{ Chronic obstructive pulmonary disease } \\
\hline Depression & $2.42(1.11-5.27)$ & $2,09(0,93-4,68)$ \\
\hline
\end{tabular}

ORc, crude odds ratio; ORa, adjusted odds ratio; a, adjusted for gender, skin, age, income, BMI, thyroid disease, asthma, angina, myocardial infarction, heart failure, COPD and depression; b, adjusted for gender, skin, income, BMI, anemia, thyroid disease, asthma, angina, myocardial infarction, heart failure, COPD and depression; c, adjusted for age, income, thyroid disease, asthma, angina, myocardial infarction, heart failure, COPD and depression; $d$, no cases. ORc, crude Odds ratio was estimated by chi-square test and adjusted odds ratios estimated by multiple logistic regression.

their breath. This sensation is secondary to the reduced cardiac output and pulmonary perfusion and is caused by decreased myocardial ischemic contractility. ${ }^{24}$ The lack of breath alone can be a presenting symptom of acute coronary syndrome. ${ }^{24}$ Brieger and colleagues reported in their study that, of 1,763 patients admitted in emergency, $8.4 \%$ had no chest pain and nearly half of them had only dyspnea. ${ }^{25}$ Regarding the association with thyroid disease, the literature describes that dyspnea is the most clinically relevant symptom and is known to cause substantial reduction in quality of life. ${ }^{26}$

This study used the self-report practice to define the presence of dyspnea and the disease, including heart failure. No diagnosis of thyroid disease, asthma, angina, myocardial infarction and COPD have been done in the Digitalis Study, so, to preserve uniformity in the definition of 
variables, we opted to use the same criteria (self-report) for $H F$, even although its diagnosis was available. The accuracy of self-report of chronic diseases is usually satisfactory. ${ }^{27}$ An important advantage of using self-reports is that this type of data collection increases the opportunities to compare international study results because there are substantial differences between health care structures in different countries, and so information from medical records often are not easily comparable. ${ }^{28}$ A prevalence of $4 \%$ selfreported HF cases in adults aged 65 years was found in previous studies, a prevalence rate lower than the $8 \%$ to $10 \%$ estimative found in other population-based studies that used the specialized medical diagnosis. ${ }^{29}$ This study pointed in the same direction. The prevalence was $8.2 \%$ in self-reported HF and $9.2 \%$ in diagnosed HF $\left(\mathrm{HF}_{\text {diag }}\right)$. Self-reported $\mathrm{HF}$ achieved $88 \%$ accuracy in relation to $\mathrm{HF}_{\text {diag }}$. Studies report that older people, women, and white individuals are more likely to report diseases, including $\mathrm{HF}^{29}$ For COPD there are reports of good accuracy, as well as for asthma, and there is always an underestimation of prevalence. ${ }^{30}$ With few exceptions, the level of education, urbanization and depressive symptoms had no effect on the accuracy of the self-reports of patients about the presence or absence of specific chronic diseases. ${ }^{28}$ These observations lead us to affirm that the analyses presented here have a good level of internal validity.

The present study has other limitations besides the fact that the diseases were self-reported, as discussed above. Its cross-sectional design prevents it from establishing dyspnea as a consequence of the diseases studied. On the other hand, the low prevalence of certain diseases caused some biologically plausible associations to not reach the significance level of 0.05 .

With the results obtained on the diseases most strongly associated with the three types of dyspnea included in the study, it can be concluded that the HF, COPD and depression, even individually, were associated with dyspnea on exertion and orthopnea. Regarding the PND and HF presented a very strong association both in the crude and the adjusted analysis, while COPD in isolation did not show any cases; which could mean that PND is a specific symptom of the COPD.

It can also be concluded that the association of these pathologies with dyspnea allowed us to see more clearly the existence of connection or not to the respiratory disorder.

The different behavior of the associations of the types of dyspnea with the major chronic diseases of patients in primary health care can help in the better characterization of patients with HF. However, it should be emphasized that clinical signs and symptoms of COPD, asthma, depression and HF, require careful interpretation by physicians in general for proper diagnosis and treatment.

\section{Conflicts of interest}

None.

\section{Acknowledgments}

Fundação municipal de Saúde de Niterói.

\section{References}

1. Hüfner A, Dodt C. Definition, primary examination and differential diagnostics in acute dyspnea. Med Klin Intensivmed Notfmed. 2015;110:465-80.

2. Ahmed A, Allman RM, Aronow WS, DeLong JF. Diagnosis of heart failure in older adults: predictive value of dyspnea at rest. Arch Gerontol Geriatr. 2004;38:297-307.

3. Tessier JF, Nejjari C, Letenneur L, Filleul L, Marty ML, Barberger Gateau P, et al. Dyspnea and 8-year mortality among elderly men and women: the PAQUID cohort study. Eur J Epidemiol. 2001; 17:223-9.

4. Ponikowski P, Voors AA, Anker SD, Bueno H, Cleland JG, Coats AJ, et al. ESC 2016 ESC Guidelines for the diagnosis and treatment of acute and chronic heart failure: The Task Force for the diagnosis and treatment of acute and chronic heart failure of the EuropeanSociety of Cardiology (ESC). Developed with the special contribution of the Heart FailureAssociation (HFA) of the ESC. Eur J Heart Fail. 2016;18:891-975.

5. de la Figuera M, Fernández J, Fernández MI, Castelló M, Canadell J. ARECO [Suitability and performance of echocardiogram in primary care]. Aten Primaria. 2012;44: 190-8.

6. Farmakis D, Parissis J, Lekakis J, Filippatos G. Acute heart failure: Epidemiology risk factors prevention. Farmakis D. Parissis J. Lekakis J. Filippatos G. Rev Esp Cardiol. 2015;68:245-8.

7. Ekundayo OJ, Howard VJ, Safford MM, MCClure LA, Arnett D, Allman RM, et al. Value of orthopnea, paroxysmal nocturnal dyspnea, and medications in prospective population studies of incident heart failure. Am J Cardiol. 2009;104: 259-64.

8. Fonseca C, Morais H, Mota T, Matias F, Costa C, Gouveia-Oliveira $A$, et al. EPICA Investigators. The diagnosis of heart failure in primary care: value of symptoms and signs. Eur J Heart Fail. 2004;6:795-800, 821-2.

9. Rosa Maria Luiza G, Mesquita Evandro T, Jorge Antonio José L, Correia Dayse MS, Lugon Jocemir R, Kang HC, et al. Prevalence of chronic diseases in individuals assisted by the family health program in niteroi, brazil: evaluation of selection bias and protocol. Int J Med Res Health Sci. 2015;4:587-96.

10. Physical status: the use and interpretation of anthropometry. Report of a WHO Expert Committee. World Health Organ Tech Rep Ser. 1995;854:1-452.

11. Kroenke K, Spitzer RL, Williams JB. The PHQ-9: validity of a brief depression severity measure. J Gen Intern Med. 2001;16:606-13.

12. Santos IS, Tavares BF, Munhoz TN, Almeida LS, Silva NT, Tams BD, et al. [Sensitivity and specificity of the Patient Health Questionnaire-9 (PHQ-9) among adults from the general population]. Cad Saude Pública. 2013;29: 1533-43.

13. Bozkurt B, Mann DL. Cardiology patient page Shortness of breath. Circulation. 2003;108:e11-3.

14. Baeza-Trinidad R, Mosquera-Lozano JD, El Bikri L. Assessment of bendopnea impact on decompensated heart failure. Eur J Heart Fail. 2017;19:111-5.

15. Albert N, Trochelman K, Li J, Lin S. Signs and symptoms of heart failure: are you asking the right questions? Am J Crit Care. 2010;19:443-52.

16. Mirza S, Clay RD, Koslow MA, Scanlon PD. COPD Guidelines: A Review of the 2018 GOLD Report. Mayo Clin Proc. 2018;93:1488-502.

17. Lainscak M, Anker SD. Heart failure, chronic obstructive pulmonary disease, and asthma: numbers, facts, and challenges. ESC Heart Fail. 2015;2:103-7.

18. Locke E, Thielke S, Diehr P, Wilsdon AG, Barr RG, Hansel N, et al. Effects of respiratory and non-respiratory factors on disability 
among older adults with airway obstruction: the Cardiovascular Health Study. COPD. 2013;10:588-96.

19. Pooler A, Beech R. Examining the relationship between anxiety and depression and exacerbations of COPD which result in hospital admission: a systematic review. Int J Chron Obstruct Pulmon Dis. 2014 29;9:315-30.

20. Scano G, Gigliotti F, Stendardi L, Gagliardi E. Dyspnea and emotional states in health and disease. Respir Med. 2013;107:649-55.

21. Dekker RL, Lennie TA, Doering LV, Chung ML, Wu JR, Moser DK. Coexisting anxiety and depressive symptoms in patients with heart failure. Eur J Cardiovasc Nurs. 2014;13:168-76.

22. Battaglia S, Benfante A, Spatafora M, Scichilone N. Breathe. Asthma in the elderly: a different disease? 2016;12:18-28.

23. Lee YS, Baek S, Ko Y, Kim MY, Lee HK, Kim TB, et al. New scoring system for the differentiation of chronic obstructive pulmonary disease and asthma. Respirology. 2015;20: 626-32.

24. Perez-David E, Rey Blas JR. Cardiopatía Isquémica: Angina de Pecho cap 6 Estudio de la incapacidad laboral por enfermedades cardiocirculatorias. Instituto Nacional de Medicina y Seguridad del Trabajo. 1998:208.
25. Brieger D, Eagle KA, Goodman SG, Steg PG, Budaj A, White $\mathrm{K}$, et al. GRACE Investigators. Acute coronary syndromes without chest pain, an underdiagnosed and undertreated high-risk group: insights from the Global Registry of Acute Coronary Events. Chest. 2004;126:461-9.

26. Siegel B, Ow TJ, Abraham SS, Loftus PA, Tassler AB, Smith RV, Schiff BA. How radiologic/clinicopathologic features relate to compressive symptoms in benign thyroid disease. Laryngoscope. 2017; 127:993-7.

27. Letamo G, Keetile M, Navaneetham K, Phatsimo M. Prevalence and correlates of self-reported chronic non-communicable diseases in Botswana: a cross-sectional study. Int Health. 2017;9:11-9.

28. Prinja S, Jeet G, Kumar R. Validity of self-reported morbidity. Indian J Med Res. 2012;136:722-4.

29. Gure TR, McCammon RJ, Cigolle CT, Koelling TM, Blaum CS, Langa KM. Predictors of self-report of heart failure in a population-based survey of older adults. Circ Cardiovasc Qual Outcomes. 2012;5:396-402.

30. Barr RG, Herbstman J, Speizer FE, Camargo CA Jr. Validation of self-reported chronic obstructive pulmonary disease in a cohort study of nurses. Am J Epidemiol. 2002:155. 